\title{
Use of Vaginal Packing in the Management of Lower Uterine Segment Atony
}

\author{
Ihsan BAGLI' 1 , Selami ERDEM1 \\ Diyarbakır, Türkiye
}

\begin{abstract}
OBJECTIVES: We aimed to evaluate the effect of vaginal packing in the management of lower uterine segment atony that it is a distinct cause of primary postpartum hemorrhage. We also set out to determine the incidence of lower uterine segment atony.

STUDY DESIGN: This is a retrospective study involving 967 births out of 25000 deliveries in one institution in the year 2018. Of 967 births were managed by the corresponding author of this study. Of 14 lower uterine segment atony patients were occurred during the study period among 967 deliveries. All patients with lower uterine segment atony were treated by vaginal packing.
\end{abstract}

RESULTS: The occurrence of postpartum hemorrhage among the study population was $57 / 967$ (5.9\%). We found the incidence of lower uterine segment atony to be $1.4 \%(14 / 967)$. Vaginal packing as a first attempt was found to be successful for controlling hemorrhage in 13/14 (92.8\%) patients with lower uterine segment atony. It was found to occur in the repeated cesarean group more than other groups, but this difference was not statistically significant $(p=0.157)$. Any complications were occurred related to packing.

CONCLUSION: Vaginal packing was found to be simple, safe, and feasible in terms of achieving hemostasis in cases of postpartum hemorrhage due to lower uterine segment atony. Vaginal packing is a potential method for preserving the uterus before further surgical application.

KEYWORDS: Atony, Lower uterine segment, Postpartum hemorrhage, Vaginal packing

Gynecol Obstet Reprod Med 2022;28(2):144-150

\section{Introduction}

The occurrence of postpartum hemorrhage (PPH) worldwide was reported to be $2 \%$ according to the World Health Organization in 2012 (1). However, at our institution, this rate of occurrence was much higher than those statistics, upon which the rate of peripartum hysterectomy was approximately $1 \%$ of PPHs in the year 2016 (2). One major reason for PPH is uterine atony or generalized hypo contractility of the uterus

1 University of Health Sciences Diyarbakir Gazi Yasargil Research and Training Hospital, Department of Obstetrics and Gynecology, Diyarbakur, Türkiye

Address of Correspondence: Ihsan Bagl

Diyarbakir Gazi Yasargil Egitim Arastirma Hastanesi Ek Bina, Urfa Yolu, Baglar,

21090 Diyarbakir, Türkiye

Email: ihsanbagli@gmail.com

Submitted for Publication: 05.10.2020 Revised for Publication: 16.10.2020 Accepted for Publication: 04.02.2021 Online Published: 10.04.2021

ORCID IDs of the authors: $\quad$ IB:0000-0002-3195-9164 SE:0000-0002-8517-5787

\begin{tabular}{c|c}
\hline $\begin{array}{c}\text { Quick Response Code: } \\
\text { 品 }\end{array}$ & Access this article online \\
\cline { 2 - 2 } & Website: www.gorm.com.tr \\
& e- mail: info@gorm.com.tr \\
\cline { 2 - 3 } & DOI:10.21613/GORM.2021.1159 \\
\hline
\end{tabular}

How to cite this article: Bagli I. and Erdem S. Use of Vaginal Packing in the Management of Lower Uterine Segment Atony. Gynecol Obstet Reprod Med. 2022;28(2):144-150 after delivery. Although it has not yet been fully entered into the jargon of obstetricians, there is also the concept of the lower uterine segment atony (LUSA) as a rare cause of PPH. Firstly in 2009, Panda et al. defined LUSA to be atony of lower uterine segment in the presence of contracted uterine fundus and exclusion of other causes of PPH (3). The term of LUSA is not widely seen in the literature that occurs after either vaginal or cesarean section delivery. Most probably, the reason for LUSA may due to a placental part that lies in the lower uterine segment. LUSA was described in a few studies however the exact incidence and treatment is lacking (3-5). There is some data such as uterine packing interventions covered with drugs or not due to bleeding from the placenta previa and placenta accreta spectrum in the lower uterine segment, and generalized uterine atony $(5,6)$. Vaginal packing has not been used so much while it is a cheap and easy application in obstetric practice. The objective of this retrospective study is to evaluate the effectiveness and safety of vaginal packing in the management of LUSA and determination of the incidence of this entity.

\section{Material and Method}

This retrospective study was conducted at a tertiary referral Hospital. The ethics committee approved the study on 18

(cc) BY Copyright ${ }^{\circ}$ 2022. Bagli et al. This article is distributed under a Creative Commons Attribution 4.0 International License. 
December 2018 with the number of 199. In our institution, 25 thousand women deliver per year. The hospital database was searched for 967 births managed by corresponding author and the patients were encountered during the study period which the year of 2018. As a definition of PPH, we used the method of visual estimation of blood loss during the postpartum period with increased shock index above 0.9 (heart rate/systolic blood pressure) (Table I) and all confirmed with decreased hematocrit levels more than 10 percent when laboratory findings were checked $(7,8)$.

Table I: Clinic and demographic characteristics of the study patients with PPH (all of them have lower uterine segment atony-LUSA)

\begin{tabular}{|c|c|c|c|c|c|c|c|c|c|}
\hline Cases & $\begin{array}{l}\text { Patients } \\
\text { age }\end{array}$ & $\begin{array}{l}\text { Case } \\
\text { summary }\end{array}$ & $\begin{array}{l}\text { Prepartum } \\
\text { Hb values } \\
\text { (gr/dl) }\end{array}$ & $\begin{array}{l}\mathrm{Hb} \text { values } \\
\text { after } \mathrm{PPH}\end{array}$ & $\begin{array}{l}\text { after treat- } \\
\text { ment con- } \\
\text { trol Hb val- } \\
\text { ues (utero- } \\
\text { tonics, } 1 \mathrm{~g} \\
\text { cephalospo } \\
\text { rin, vaginal } \\
\text { packing, } \\
\text { and blood } \\
\text { products) }\end{array}$ & $\begin{array}{l}\text { vaginal } \\
\text { packing } \\
\text { removal } \\
\text { time after } \\
\text { placement }\end{array}$ & $\begin{array}{c}\text { Complicati } \\
\text { ons / } \\
\text { Morbidities } \\
\text { (infections, } \\
\text { occult } \\
\text { bleeding, } \\
\text { further sur- } \\
\text { gical inter- } \\
\text { ventions }\end{array}$ & $\begin{array}{l}\text { Blood } \\
\text { products }\end{array}$ & Risk factor \\
\hline 1 & 28 & $\begin{array}{l}\text { G1, SVD (with epi- } \\
\text { siotomy) } \\
\text { Birth weight: } 3350 \mathrm{~g} \\
\text { SI: } 0.92\end{array}$ & 11.1 & 8.5 & 9.1 & 6 hours & None & \multicolumn{2}{|c|}{$\begin{array}{l}1 \cup \mathrm{ES}+1 \text { UNon } \\
\text { FFP }\end{array}$} \\
\hline 2 & 23 & $\begin{array}{l}\text { G1, SVD (with epi- } \\
\text { siotomy) } \\
\text { Birth weight: } 2900 \mathrm{~g} \\
\text { SI: } 1.1\end{array}$ & 10.8 & 7.7 & 7.8 & 7 hours & None & $\begin{array}{l}\text { Non } \\
\text { (refused to } \\
\text { take blood } \\
\text { products }\end{array}$ & $\begin{array}{l}\text { Prolonged } \\
\text { labor }\end{array}$ \\
\hline 3 & 38 & $\begin{array}{l}\text { G6, SVD } \\
\text { Birth weight: } 3500 \mathrm{~g} \\
\text { SI: } 1.3\end{array}$ & 9.6 & 6.2 & 9.3 & 6 hours & None & $\begin{array}{l}2 \cup \mathrm{ES}+2 \\
\cup \mathrm{FFP}\end{array}$ & $\begin{array}{l}\text { Polyhydra } \\
\text { mnios }\end{array}$ \\
\hline 4 & 31 & $\begin{array}{l}\text { G3 (prior C/S) } \\
\text { Birth weight: } 3600 \mathrm{~g} \\
\text { SI: } 1.2\end{array}$ & 10.9 & 6.3 & 9.7 & 8 hours & None & $\begin{array}{l}3 \cup \text { ES + } 3 \\
\text { U FFP }\end{array}$ & $\begin{array}{l}\text { emergency } \\
\mathrm{C} / \mathrm{S}\end{array}$ \\
\hline 5 & 30 & $\begin{array}{l}\text { G7 (prior 2xC/S) } \\
\text { Planned C/S } \\
\text { Birth weight: } 2980 \mathrm{~g}\end{array}$ & 12.2 & 8.4 & 11.3 & 6 hours & None & $\begin{array}{l}2 \cup \mathrm{ES}+2 \\
\text { U FFP }\end{array}$ & $\mathrm{C} / \mathrm{S}$ \\
\hline 6 & 33 & $\begin{array}{l}\text { G4, SVD } \\
\text { Birth weight: } 3300 \mathrm{~g} \\
\text { SI: } 0.97\end{array}$ & 11.9 & 8.7 & 8.9 & 6 hours & None & Non & Non \\
\hline 7 & 32 & $\begin{array}{l}\text { G3 (prior } 3 x C / S \text { ) } \\
\text { Birth weight: } 3050 \mathrm{~g} \\
\text { SI: } 0.99\end{array}$ & 10.8 & 8.1 & 10.4 & 6 hours & None & $\begin{array}{l}2 \cup \mathrm{ES}+1 \\
\cup \text { FFP }\end{array}$ & $\begin{array}{l}\text { emergency } \\
\mathrm{C} / \mathrm{S}\end{array}$ \\
\hline 8 & 34 & $\begin{array}{l}\text { G1, SVD (with epi- } \\
\text { siotomy) } \\
\text { Birth weight: } 3300 \mathrm{~g} \\
\text { SI: } 0.91\end{array}$ & 13.6 & 10.7 & 10.4 & 6 hours & None & Non & $\begin{array}{l}\text { Prolonged } \\
\text { labor (done } \\
\text { vacuum ex- } \\
\text { traction) }\end{array}$ \\
\hline 9 & 19 & $\begin{array}{l}\text { G1 (breech presen- } \\
\text { tation) } \\
\text { Birth weight: } 2950 \mathrm{~g} \\
\text { Sl. } 14\end{array}$ & 11.2 & 7.7 & 10.1 & 7 hours & None & $\begin{array}{l}2 \cup \mathrm{ES}+2 \\
\cup \mathrm{FFP}\end{array}$ & $\begin{array}{l}\text { emergency } \\
\mathrm{C} / \mathrm{S}\end{array}$ \\
\hline
\end{tabular}


10 43

G6 (prior C/S)

Performed

planned $\mathrm{C} / \mathrm{S}$

Birth weight: $2750 \mathrm{~g}$

SI: 1.2

11

12

30

G3, SVD

Birth weight: $3300 \mathrm{~g}$

SI: 1.5

G5, SVD

Twin pregnancy

(cephalic-cephalic

presentation)

Birth weight: 2300-

$2700 \mathrm{~g}$

SI: 1.1

13

26

G3 (prior 2xC/S)

Birth weight: $2450 \mathrm{~g}$

SI: 1

14

$$
\begin{array}{ll}
22 & \text { G2 (prior C/S) } \\
& \text { Birth weight: } 2900 \mathrm{~g} \\
& \text { SI: } 0.94
\end{array}
$$

10.6

7.1

9.3

8 hours

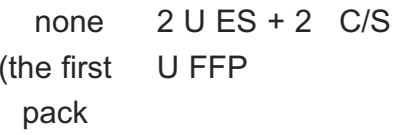

dropped

down

sponta-

neously

after 1

hour and

then the

second

pack was

placed)

8.8

5.9

9.1

7 hours

None

$3 \cup \mathrm{ES}+3$ Non

U FFP

10.3

7.9

8.2

6 hours

none (just Non

fever)

Twin preg-

nancy

10.1

7.2

9.6

6 hours

None

emergency

$2 U E S+2 \quad C / S$

U FFP

11.3

8.2

10.1
Non

emergency

$\mathrm{C} / \mathrm{S}$

G: gravida, SVD: Spontaneous vaginal delivery, Hb: Hemoglobin, ES: Erythrocyte suspension FFP: Fresh frozen Plasma, C/S: Cesarean section. SI: Shock index

The second stage of labor is the time between full dilated cervix uteri and expulsion of the fetus, prolonged second stage of labor is defined as $>2 \mathrm{~h}$ without and $>3 \mathrm{~h}$ with epidural analgesia in nulliparous women, and $>1$ hour without and $>2 \mathrm{~h}$ with epidural analgesia in parous women (9). Our hospital's annual number of birth is around 25 thousand. Considering this density, sufficient infrastructure is not available for epidural anesthesia. After 1 hour of full dilation of the cervix, if the fetal head is beneath the ischial spines, patients are taken to the lithotomy position and encouraged to push the baby in our clinic. Routinely, as a part of active management of the third stage of labor, uterotonics were administered to all patients according to the last Cochrane systematic review for prevention of atony (10). Active management of the third stage of labor included iv oxytocin administration (10 units in $500 \mathrm{~mL}$ normal saline), early cord clamping, and traction of the cord immediately after delivery.

Postpartum hemorrhage occurred in 57 deliveries among this study's population ( $\mathrm{n}=967)$. The rates of PPH were calculated in terms of the causes of hemorrhage. Generalized uter- ine atony, genital lacerations, and placental retentions occurred in 32, 6, and 5 patients respectively and they were treated with appropriate methods. Of 14 patients diagnosed with LUSA as a cause of PPH. LUSA was diagnosed by existing well contracted uterine fundus, no retained placental products, and no genital tract lacerations with careful inspection of the vagina. For the exclusion of the retained products of conception and controlling the Kerr incisions or integrity of the uterus and any intraabdominal hematoma, ultrasonography was used. Before applying vaginal packing, uterine massage was applied to all patients simultaneously with medical treatment, and then bimanual compression was applied to patients who continued bleeding. After these, when the bleeding continued, vaginal packing was applied within three or five minutes. Vaginal packing was performed using 10-13 gauze sponges. Each gauze sponge was approximately $20 \mathrm{~cm}$ long by $4 \mathrm{~cm}$ wide. Usually, gauze sponges were connected. Our purpose was to compress the lower uterine segment between the well contracted uterine corpus and gauzes. The vaginal packing was performed tightly. During the procedure, $2 \mathrm{~g}$ cephalosporin were given to the patients with LUSA. All pa- 
tients were followed continuously monitoring vital signs and performing a vulvar inspection in case of persistent hemorrhage. Foley catheter was used in all LUSA cases for prevention of urinary retention and inspection of the vital signs. No patient with LUSA had a low-lying placenta (to have $2 \mathrm{~cm}$ distance between the edge of placenta and internal cervical ostium) or placental abnormalities, according to their previous sonographic results but nobody had placenta where placed uterine fundus totally, most of the placentas almost completely or partially filled the lower uterine segment.

The study population was divided into four groups: the primiparous vaginal delivery group $(\mathrm{n}=195)$, the multiparous vaginal delivery group $(\mathrm{n}=471)$, the primary cesarean group $(n=90)$, and the repeated cesarean group $(n=211)$, respectively. These groups were created to understand that LUSA is seen more frequently in which group. Of these, we focused only on 967 deliveries exhibiting cases of PPH with LUSA by mainly looking at how effective vaginal packing was in the management of the LUSA was studied. The frequency of the LUSA was revealed and in which group it was seen more frequently, were calculated statistically. Ethics committee approval was received for this study from the ethics committee of Health Science University Diyarbakir Gazi Yasargil Training and Research Hospital (no: 28.12.2018/199).

\section{Statistical Analysis}

We performed all statistical analysis using SPSS software (Version 21.0; SPSS Inc., Chicago, IL, USA). We calculated demographic data using descriptive statistics. Number and percentage were used to describe the data. Kolmogorov-Smirnov test was used to determine whether the variables were in a normal distribution. Pearson's chi-square test, which enables us to evaluate categorical variables, was used to evaluate the causes of PPH seen in different delivery groups. We considered a twosided $p$-value $<0.05$ as significant for all analyzes.

\section{Results}

The medical records of these 14 patients with LUSA are summarized in Table I, including demographic, antepartum, intrapartum, and postpartum data. Of 14 patients' mean age was $29 \pm 7.49($ Mean \pm SD).

The occurrence of PPH among this study's population was $5.9 \%$ (57/967). Likewise, we found the occurrence of LUSA to be $1.4 \%$ (14/967). Generalized uterine atony, genital lacerations, and placental retentions occurred in 32 (3.3\%), 6 $(0.6 \%)$, and $5(0.5 \%)$ patients respectively and they were treated with appropriate methods.

Three patients in primiparous vaginal delivery group 3/195 (\%1.15), four in multiparous vaginal delivery group 4/471 $(0.84 \%)$, one in primiparous cesarean section group 1/90 $(1.10 \%)$, and six in repeated cesarean group 6/211 (2.84\%) had LUSA (Table II). Despite not being of statistical significance, PPH due to LUSA was found to occur the most frequently in the repeated cesarean group $(p=0.157)$.

Lower uterine segment atony was controlled successfully in 13 of $14(92.8 \%)$ patients using vaginal packing at the first attempt. Second vaginal packing was needed in one patient due to dropping of the vaginal packing spontaneously and hemostasis was achieved in this patient finally after reinsertion. No general anesthesia was used for vaginal packing. No maternal mortality or morbidity occurred. Transfusion of blood products was not given to $\% 36$ of the patients with LUSA. The vaginal packings were removed after 6 to 8 hours after insertion. No adverse effects including perineal or ab-

Table II: Comparison of postpartum hemorrhage, reasons according to delivery groups

\begin{tabular}{|c|c|c|c|c|c|}
\hline Reasons of PPH & $\begin{array}{l}\text { Primiparous } \\
\text { Vaginal Birth Group } \\
\mathrm{n}(\%)\end{array}$ & $\begin{array}{l}\text { Multiparous } \\
\text { Vaginal Birth Group } \\
\mathrm{n}(\%)\end{array}$ & $\begin{array}{l}\text { Primary } \\
\text { Cesarean Group } \\
\mathrm{n}(\%)\end{array}$ & $\begin{array}{l}\text { Repeated } \\
\text { Cesarean Group } \\
\text { n (\%) }\end{array}$ & $p^{*}$ \\
\hline \multicolumn{6}{|l|}{ LUSA } \\
\hline No & $192(98.5)$ & $467(99.2)$ & 89 (98.9) & $205(97.2)$ & 0.157 \\
\hline Yes & $3(1.5)$ & $4(0.8)$ & $1(1.1)$ & $6(2.8)$ & \\
\hline \multicolumn{6}{|l|}{ Generalized Atony } \\
\hline No & $193(99)$ & $449(95.3)$ & $85(94.4)$ & $208(98.6)$ & 0.022 \\
\hline Yes & $2(1)$ & $22(4.7)$ & $5(5.6)$ & $3(1.4)$ & \\
\hline \multicolumn{6}{|l|}{ Genital Laceration } \\
\hline No & $191(97.9)$ & $469(99.6)$ & $90(100)$ & $211(100)$ & 0.018 \\
\hline Yes & $4(2.1)$ & $2(0.4)$ & $0(0)$ & $0(0)$ & \\
\hline \multicolumn{6}{|c|}{ Placenta Retention } \\
\hline No & $194(99.5)$ & $466(98.9)$ & $90(100)$ & $211(100)$ & 0.476 \\
\hline Yes & $1(0.5)$ & $4(1.1)$ & $0(0)$ & $0(0)$ & \\
\hline
\end{tabular}

${ }^{*} p<0.05$ is accepted as significant. PPH: postpartum hemorrhage, LUSA: lower uterine segment atony 
dominal hematoma or occult bleeding were observed. Fever was observed in one patient with the possibility of an adverse effect of prostaglandin E1. Five patients were not given blood products, one of them had refused to take red blood cells. Owing to timely intervention and medication, the necessity of blood transfusion was prevented in four cases. All patients with LUSA were discharged between 24th and 36th hours postpartum.

\section{Discussion}

Lower uterine segment atony has gained popularity among a limited number of obstetricians after a proposal of this entity by Panda et al. since 2009 (3). Vaginal packing may be regarded as a simple life-saving technique in low-income countries in LUSA patients. Our study suggested vaginal packing as an effective method in controlling LUSA.

Almost all previously reported cases of gauze packing in obstetric and gynecological practice include uterine gauze packing, however, this procedure gradually fell from favor because of concerns related to overlooked bleeding and infection (11). Different from previous studies, we inserted gauzes into the vagina instead of the uterine cavity. Inserting gauzes into the vagina for controlling LUSA and removal in a short time while contributing to the results of any infection in our cases.

The pushing up the uterus with a vaginal pack provided strong hemostasis in our LUSA patients. The mechanism of hemostasis probably depended on two mechanisms: 1) flask lower uterine segments compressed between the well contracted uterine fundus and vaginal packing, and 2) due to impaired blood flow through the uterine artery owing to an elevated uterus. Koyama et al's findings suggested a second mechanism (12). Compressing the uterus may lead to elongated and curved uterine arteries in a vertical direction, a narrowing of intravascular space and obstructing the vessels, and the reduction of uterine blood flow. During the postpartum period, uterine involution also leads to a decrease in blood flow with increased vascular resistance (13).

Unlike Panda et al., we did not use any curettage-based methods. We only removed the hematoma accumulated in the lower uterine segment with a mounted buffer and used 10 to 13 gauzed sponges according to the width of the patient's vagina. Each gauze was $20 \mathrm{~cm}$ long by $4 \mathrm{~cm}$ wide and these were firmly attached, thus it was provided to prevent oblivion in the vagina any piece of gauze.

Hamdy described a novel hypothetical technique in which the physician pulls the cervix through vagina using two ovum pens for 90 seconds to prevent PPH with atony (14). However, this technique may block a provider for a long time when PPH occurs. Conversely, Yüksel spent nearly 30 minutes on a patient applying a similar technique in order to treat LUSA (15). This maneuver may damage the cervix uteri, but the maneuver is applicable for some mobile uteri. Schmid et al. stated that it is difficult to design randomized controlled trials on the management of potentially life-threatening PPH. Therefore, case studies are important (16). In our retrospective preliminary study, patients recovered dramatically. The elevated heart rate regressed to a normal range after vaginal packing immediately. During the initial first vaginal packing, we had excellent results in almost all of the cases except for one. The only complaints mentioned were pain and distention of the vagina. Therefore, the bladder catheter seemed to be mandatory for both vital follow-ups, in order not to produce urinary retention in patients. We think that even a midwife can comfortably apply vaginal packing and refer to the patient who has LUSA.

There are several packing methods, including Harbi et al.'s study citing a patient with placenta previa/accreta, whereupon they used uterovaginal packing to prophylactic prevent placental bed bleeding during cesarean section. Respectively, this was found successful among their patients (17). No patient had any complaints about placental insertion abnormalities in our study. Cohen et al. suggested that some patients have uterine muscular deficiency especially at lower uterine segments (18). The muscular loosening in the lower uterine segment is more common because of either prolonged labor and/or repeated emergency cesareans. We know that uterine contractions start from the fundus and spread to the lower segment; therefore, a repeated cesarean section may create a blockage for passing the contractions from the fundus to the lower segment. Furthermore, we observed that emergency repeated cesarean sections may be accepted as the main risk factor in our cases. In our study, the LUSA rate was higher in the repeated cesarean group, albeit this was not statistically significant. Further studies may be required for these issues. Another issue is that according to LUSA patients' previous sonographic results nobody had a placenta that was placed in the uterine fundus. Nearby whole patient's placentas were related to lower uterine segments partially or mostly. Thus, the source of hemorrhage can be explained in patients with LUSA. Although there are some descriptive publications about LUSA $(3,4,15)$, the general term of LUSA may not be known well or used by some obstetricians, for example, Huque S et al. (19) published a study that included $20.000 \mathrm{PPH}$ (caused by atony, trauma/tears, Previa/accreta, others/unknown) but they did not use the term of LUSA as a reason of PPH. Maybe, there were some cases of LUSA in their other/unknown group. The current term of LUSA was used in Dueckelmann et al. study in 2019, but they did not state how many subjects had LUSA among patients with PPH. They used chitosan covered uterine gauze packing for LUSA patients successfully in their study (5). In a study, compressing the lower uterine segment was found to be important in preventing or stopping PPH, particularly when the placental bed placed the lower uterine segment (20). Contractions of the uterine body can reject the balloon tamponade system through the vagina. A study stated that displacement of the applied uterine balloon occurs in about $10 \%$ 
of cases (21). Additionally, Dueckelman et al. stated that intrauterine placement of the balloon tamponade system sometimes may be difficult and after cesarean section, uterine perforation or scar dehiscence can occur due to the Bakri system $(5,22)$. It is claimed in the ACOG 2017 practice bulletin no:183 that stubborn lower uterine segment atony bleeding can be stopped with balloon tamponade (23). However, this claim does not refer to any study. Therefore, as we know that LUSA has a well contracted uterine body, and there are difficulties for placement of balloons to the lower uterine segment, we did not use any balloon system.

In conclusion, our study suggested that vaginal packing was a highly successful method in the management of LUSA patients. This study has the potential to heighten awareness on LUSA as well as decrease the further surgical interventions, thus preventing morbidity. LUSA has the potential to investigate in further studies.

Acknowledgment: None

Conflict of interest: The authors declare that they have no competing interest.

Funding: None

Ethics: All participants signed informed written consent before being enrolled in the study. The study was reviewed and approved by the ethics committee of Health Science University Diyarbakur Gazi Yasargil Training and Research Hospital (Ethics approval reference number: 199 date: 28.12.2018). All procedures were performed according to the Declaration of Helsinki.

Availability of data and materials: The data supporting this study is available through the corresponding author upon reasonable request.

Authors' Contributions: IB contributed to the design of the study, written of manuscript, data collection, Dr. SE took the role for statistical analysis, drafting the manuscript.

\section{References}

1. WHO Recommendations for the Prevention and Treatment of Postpartum Haemorrhage. Geneva: World Health Organization; 2012. WHO Guidelines Approved by the Guidelines Review Committee.

2. Tahaoglu AE, Balsak D, Togrul C, Obut M, Tosun O, Cavus Y, et al. Emergency peripartum hysterectomy: our experience. Ir J Med Sci. 2016;185(4):833-838. Doi: 10. 1007/s11845-015-1376-4.

3. Panda B, Laifer S, Stiller R, Kleinman G. Primary atony of the lower uterine segment as a distinct cause of early postpartum haemorrhage: a case series and management recommendations. J Obstet Gynaecol. 2009;29(7):628-32. Doi: 10.1080/01443610903114493.

4. Gill P, Patel A, Van Hook JW. Uterine Atony. 2020 Jul 10. In: StatPearls [Internet]. Treasure Island (FL): StatPearls Publishing; 2020 Jan. PMID:29630290.
5. Dueckelmann AM, Hinkson L, Nonnenmacher A, Siedentopf JP, Schoenborn I, Weizsaecker K, et al. Uterine packing with chitosan-covered gauze compared to balloon tamponade for managing postpartum hemorrhage. Eur J Obstet Gynecol Reprod Biol. 2019;240:151-155. Doi: 10.1016/j.ejogrb.2019.06.003.

6. El-Refaey H, Rodeck C. Post-partum haemorrhage: definitions, medical and surgical management. A time for change. Br Med Bull. 2003;67:205-17. Doi: 10.1093/ $\mathrm{bmb} / \operatorname{ldg} 016$.

7. Gharoro EP, Enabudoso EJ. Relationship between visually estimated blood loss at delivery and postpartum change in haematocrit. J Obstet Gynaecol. 2009;29(6):517-520. Doi: $10.1080 / 01443610903003159$.

8. Tanacan A, Fadiloglu E, Unal C, Beksac MS. Importance of shock index in the evaluation of postpartum hemorrhage cases that necessitate blood transfusion. Women Health. 2020;60(9):1070-8. Doi: 10.1080/03630242. 2020.1802638 .

9. American College of Obstetrics and Gynecology Committee on Practice Bulletins-Obstetrics. ACOG Practice Bulletin Number 49, December 2003: Dystocia and augmentation of labor. Obstet Gynecol. 2003;102 (6):1445-54. Doi: 10.1016/j.obstetgynecol.2003.10. 011.

10. Begley CM, Gyte GM, Devane D, McGuire W, Weeks A, Biesty LM. Active versus expectant management for women in the third stage of labour. Cochrane Database Syst Rev. 2019;2(2):CD007412. Doi: 10.1002/14651858. CD007412.pub5.

11. Cunningham FG, Leveno KJ, Bloom SL, Hauth JC, Rouse DJ, Spong CY. Obstetrical Hemorrhage. In: Cunningham FG, Leveno KJ, Bloom S, Gilstrap L, editors. Williams Obstetrics, 23rd edition. New York: McGraw-Hill; 2010. p. $757-803$.

12. Koyama S, Maeda M, Kobayashi M, Tanaka Y, Kubota S, Nakamura R, et al. Angiographic findings after vaginal gauze packing: New insight into an old technique. J Obstet Gynaecol Res. 2013;39(6):1212-6. Doi: 10.1111/jog. 12037.

13. Sohn C, Fendel H, Kesternich P. Involution-induced changes in arterial uterine blood flow. Z Geburtshilfe Perinatol. 1988;192(5):203-9. PMID: 3062954.

14. Hamdy A. A new maneuver for prevention of postpartum haemorrhage. J Obstet Gynaecol India. 2015;65(4):241-5. Doi: 10.1007/s13224-014-0592-6.

15. Yüksel H. A novel approach to primary lower uterine segment atony. Taiwan J Obstet Gynecol. 2015;54(4):452-4. Doi: 10.1016/j.tjog.2014.05.010.

16. Schmid BC, Rezniczek GA, Rolf N, Saade G, Gebauer G, Maul H. Uterine packing with chitosan-covered gauze for control of postpartum hemorrhage. Am J Obstet Gynecol. 2013;209(3):225.e1-5. Doi: 10.1016/j.ajog.2013.05.055.

17. Al-Harbi NA, Al-Abra ES, Alabbad NS. Utero-vaginal 
packing. Seven years review in the management of post partum hemorrhage due to placenta previa/accreta at a maternity hospital in Central Saudi Arabia. Saudi Med J. 2009;30(2):243-6. PMID: 19198714.

18. Cohen WR. Postpartum hemorrhage and hemorrhagic shock. In: Cherry and Merkatz's, editors. Complications of pregnancy. London: Lippincott Williams and Wilkins. 5th ed.; 2000. Ch.51, p 803

19. Huque S, Roberts I, Fawole B, Chaudhri R, Arulkumaran S, Shakur-Still H. Risk factors for peripartum hysterectomy among women with postpartum haemorrhage: analysis of data from the WOMAN trial. BMC Pregnancy Childbirth. 2018;18(1):186. Doi: 10.1186/s12884-0181829-7.

20. Cho HY, Park YW, Kim YH, Jung I, Kwon JY. Efficacy of intrauterine bakri balloon tamponade in cesarean section for placenta previa patients. PLoS One. 2015;10 (8):e0134282. Doi: 10.1371/journal.pone.0134282.

21. Wright CE, Chauhan SP, Abuhamad AZ. Bakri balloon in the management of postpartum hemorrhage: a review. Am J Perinatol. 2014;31(11):957-64. Doi: 10.1055/s-00341372422 .

22. Leparco S, Viot A, Benachi A, Deffieux X. Migration of Bakri balloon through an unsuspected uterine perforation during the treatment of secondary postpartum hemorrhage. Am J Obstet Gynecol. 2013;208(6):e6-7.

23. Committee on Practice Bulletins-Obstetrics. Practice Bulletin No. 183: Postpartum Hemorrhage. Obstet Gynecol. 2017;130(4):e168-e186. Doi: 10.1097/AOG. 0000000000002351 . 